\title{
Waardenburg Syndrome Type 2: A Report of Three Cases in South-west Nigeria
}

\author{
Betiku AO*, Akinola MA, Jagun OO, Oluyemi OY, Salami OF
}

Department of Surgery, Ben Carson School of Medicine, Babcock University, Ilishan Remo, Ogun State, Nigeria

*Correspondence: Dr AO Betiku, Department of Surgery, Ben Carson School of Medicine, Babcock University, PMB 1, Ilishan Remo, Ogun State. Email: betikua@babcock.edu.ng; ORCID http://orcid.org/0000-0002-2126-1205.

\section{Summary}

This report is about ocular and audiometric findings in three children with Waardenburg syndrome Type 2 attending Special Education Centres in Nigeria.

Two female children and a male child aged 10, 13 and 5 years respectively had ocular examination and audiometric evaluation using inter-acoustics eclipse ASSR (Serial number 0933518) for auditory steady-state response audiometry (ASSR). The ocular features included bilateral hypoplastic blue irides and bilateral hypopigmented fundi while ASSR showed severe to profound sensorineural hearing loss. The three children had mutism hence they used sign languages for communication.

There is a need for early detection of this condition, health education and planned rehabilitation.

Keywords: Auditory Steady State Response Audiometry (ASSR), Blue irides, Nigeria, Sensorineural hearing loss, Waardenburg syndrome Type 2.

\section{Introduction}

Waardenburg Syndrome (WS) was first described in 1951 by a Waardenburg PJ. [1] It is a rare genetic disorder characterized by abnormal pigmentation of the hair, skin, eyes and minimal facial abnormalities and congenital sensorineural hearing loss. ${ }^{[2,3]}$ The incidence of this syndrome is approximately $1: 40,000$ population and it accounts for $3 \%$ of the congenital hearing loss. ${ }^{[2]}$ It has no racial or ethnic predilection and no sex predilection. [4,5] In Nigeria, Ahmed et al examined students between the ages of 10 and 19 years in a
School for the deaf and the blind and reported that $0.65 \%$ of the students had WS Type $1^{[6]}$

This syndrome is genetically and clinically heterogeneous, with four subtypes. WS Type 1 (WS1) can be diagnosed using the WS Consortium Diagnostic Criteria (Table I), in the presence of two major features or one major feature with two minor features. [3] WS Type 2 lacks dystopia canthorum (lateral displacement of the media canthi) while WS Type 3 is a severe form of WS Type 1 with associated limb defects. WS Type 4 is characterised by Hirschsprung disease. [3] 
Table I: Waardenburg syndrome consortium diagnostic criteria

\begin{tabular}{ll}
\hline Major Criteria & Minor Criteria \\
\hline Congenital sensorineural hearing loss & Skin hypopigmentation(congenital leukoma) \\
White forelock, hair hypopigmentation & Synophys/medial eyebrow flare \\
\hline Pigmentation abnormality of the iris & Broad/high nasal root, prominent columella \\
\hline Complete heterochromia iridium & Hypoplastic alae nasi \\
\hline Partial/segmental heterochromia & Premature grey hair (age <30years) \\
\hline Hypoplastic blue rides or brilliant blue eyes & \\
\hline Dystopia canthorum, Waardenburg index (W index) $>1.95$ & \\
\hline Affected first-degree relative & \\
\hline
\end{tabular}

WS is an autosomal inherited disorder with genetic heterogeneity which results from the absence of melanocytes from the stria vascularis of the cochlea, the hair, the eyes and the skin. WS Type 1 and Type 2 are inherited as autosomal dominant traits with variable penetrance and expressivity. Five genes have been implicated in all the types of WS: paired box 3 (PAX3) gene is found in most cases of WS Types 1 and 3, microphthalmia-associated transcription factor (MITF) gene in WS Type 2, endothelin-3 (EDN3) in WS Type 4, although it is associated with mutations of this gene and its receptor endothelin receptor type B (EDNRB) gene, or in SRY (sex determining region $\mathrm{Y}$ )-box 10 (SOX10) gene. About $15 \%$ of cases of WS Type 2 is caused by mutations in MITF. (7-9] However, the exact developmental sequence in which this gene acts remains unclear.

The characteristic features of WS include dystopia, broad and high nasal root, synophyrys, partial or total heterochromia iris, fundal changes, white forelock and congenital sensorineural hearing loss. [10] The different types of WS exhibit high variation in presentation which makes it difficult to determine its severity. [4] Genetic analysis is still being done to fully understand the genetic basis of WS.
WS is associated with hearing impairment. Subjective audiometry demands the cooperation and subjective responses of the patient hence objective audiometry is the preferred method in the evaluation of these patients. This is not readily available in most hospitals in our environment. The hearing impairment leads to lack of speech development which results in difficulty with learning and communication. Therefore, there is a need to create more awareness about this syndrome in order to enable early detection of hearing impairment and management. The objective of this report is to describe the ocular and audiometric findings in three Nigerian children with Waardenburg syndrome Type 2 attending Special Education Centres within a State in Nigeria. This is necessitated by the rarity of the condition and paucity of reports in Nigeria.

Evaluation of the suspected cases of WS Type 2

We report three children out of the five children who met the diagnostic criteria for WS Type 2. These three included a male and two females (aged 5, 10, 13 years respectively) who were discovered at Special Education Centres in a south-western state in Nigeria during a research trip to the schools between 
the months of March and May 2017. The other two children were excluded from this report because their parents withheld consent. The children were formally referred to our institution where they had full ophthalmological and audiological examinations and audiometric assessment.

Communication was mainly limited to the use of sign language.

Ethical clearance for this report was obtained from the Babcock University Health and Research Ethics Committee. Written informed consent was also obtained from the parents of the three children being reported and the principles of Helsinki declaration was adhered to. The medical history was obtained from the mothers.

Visual acuity and ocular examination, including dilated fundoscopy, was done with a slit lamp and $+78 \mathrm{D}$ lens along with binocular indirect ophthalmoscope. The inner and outer intercanthal and inter-pupillary distances were measured with a transparent metre rule. The $\mathrm{W}$-index was calculated using the formula:

$\mathrm{W}=\mathrm{X}+\mathrm{Y}+\mathrm{a} / \mathrm{b}$,

$X=(2 a-0.2119 c-3.909) / c$

$\mathrm{Y}=(2 \mathrm{a}-0.2479 \mathrm{~b}-3.909) / \mathrm{b}$

-where ' $a$ ' is the inner inter-canthal distance, ' $b$ ' is inter-pupillary distance and $c$ is the outer inter-canthal distance. [3] A W-index greater than 1.95 is indicative of dystopia canthorum. The central corneal thickness was measured with ultrasonic SUOER ophthalmic A scan pachymeter SW 100 (model no GI 090760982 $\mathrm{SN} / 0037 \mathrm{CP}$ ) at $55 \mathrm{~Hz}$ following topical application of amethocaine drops. An audiological examination was also carried out and ASSR was done with inter-acoustic eclipse device without sedation. The procedure was explained to the patients using the sign language. The sound level was adjusted until the hearing threshold was obtained.

\section{Individual Cases}

\section{Case 1}

This was a 5-year old male with hearing loss in both ears and inability to talk from infancy and blue coloured eyes. He was a product of full-term pregnancy. There was no history of maternal illness during the antenatal period and no neonatal/childhood febrile illness or exposure to ototoxic drugs. The motor developmental milestones were not delayed. There was no history of similar conditions among other members of her family.

Physical examination revealed no physical or facial abnormalities. Ocular findings included visual acuity of at least $6 / 24$ in both eyes (using hundred and thousand sweet test), decreased bilateral central corneal thickness (right eye $482 \mu \mathrm{m}$ and left eye $504 \mu \mathrm{m}$ ), bilateral complete hypoplastic blue irides, hypopigmented fundi and no dystopia canthorum (Figure 1).

The inner inter-canthal distance was $28.5 \mathrm{~mm}$, the outer inter-canthal distance was $86.5 \mathrm{~mm}$, the inter-pupillary distance was $58 \mathrm{~mm}$ and $\mathrm{W}$ index was 1.56.

Auditory Steady State Response Audiometry (ASSRA) showed severe to profound sensorineural hearing loss as shown in Figure 2. 


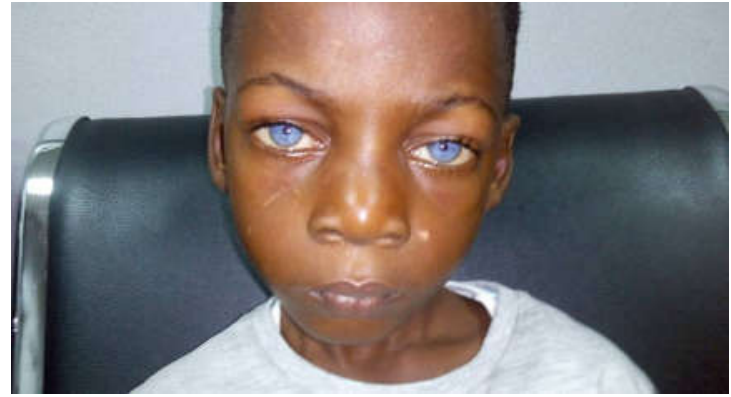

Figure 1: Bilateral complete hypoplastic blue irides in Case 1

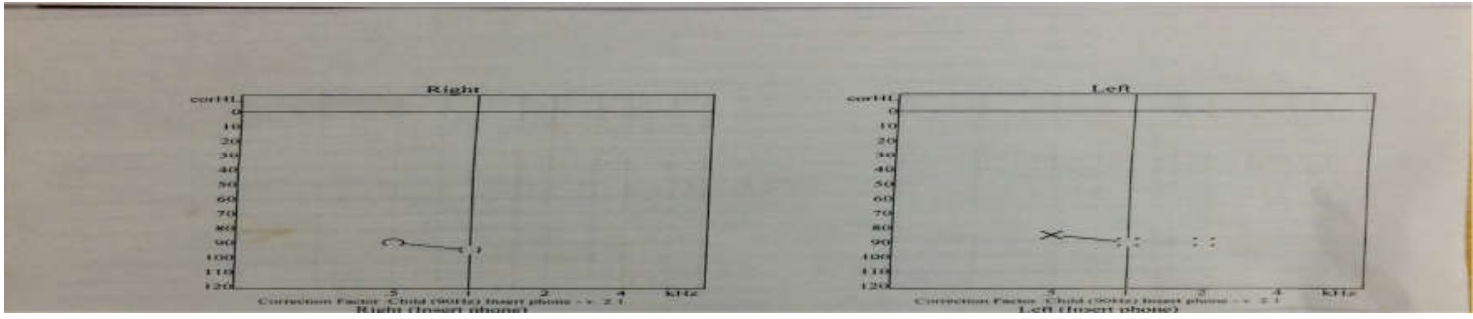

Figure 2: Audiometric assessment report on Case 1 showing severe to profound sensorineural hearing loss

\section{Case 2}

This was a 10-year old female with bilateral hearing loss from infancy and inability to talk. She was a product of full-term pregnancy. There was no history of maternal illness during the antenatal period and no neonatal/childhood febrile illness or exposure to ototoxic drugs. The motor developmental milestones were not delayed. There was no history of similar complaints among other members of her family.

Physical examination revealed no facial or physical abnormalities.

Ocular examination revealed visual acuity of 20/30 with the illiterate E-chart, bilateral complete hypoplastic blue irides, bilateral peripapillary atrophy, hypopigmented fundi and no dystopia canthorum (Figure 3). The inner inter-canthal distance was $32 \mathrm{~mm}$, the outer inter-canthal distance was $85.5 \mathrm{~mm}$, the inter-pupillary distance was $58 \mathrm{~mm}$ and the $\mathrm{W}$ index was 1.83 .

ASSRA showed severe to profound sensorineural hearing loss (Figure 4).

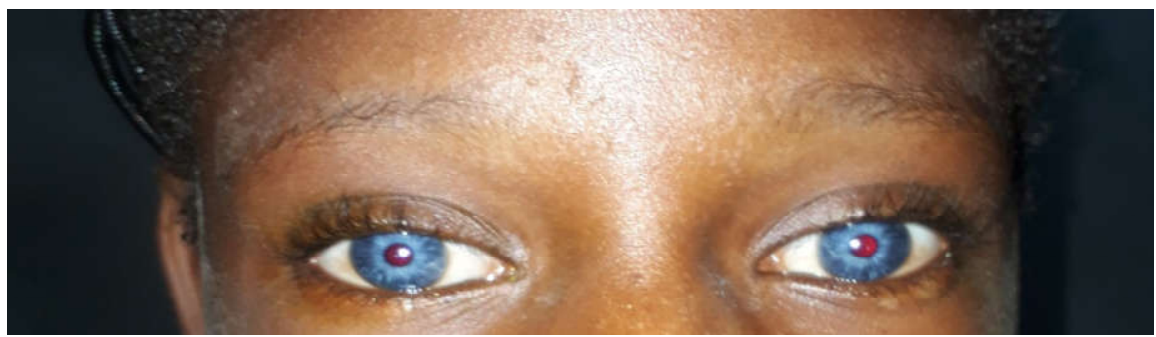

Figure 3: Bilateral complete hypoplastic blue irides in Case 2 


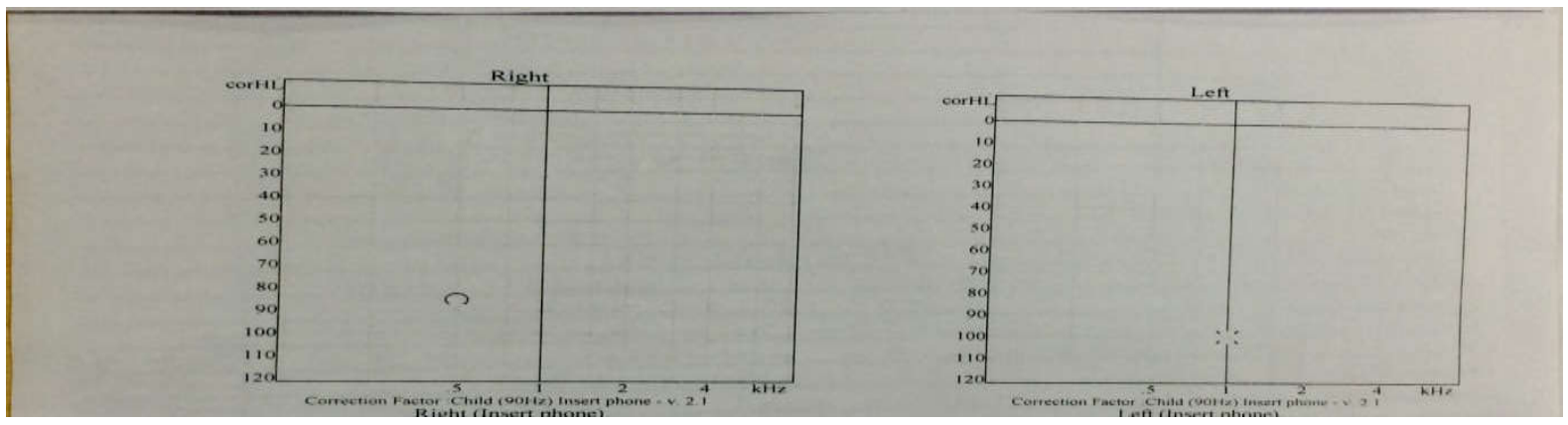

Figure 4: Audiometric profile showing severe to profound sensorineural hearing loss in Case 2

\section{Case 3}

This was a 13-year old female with bilateral hearing loss and inability to speak. She was a product of full-term pregnancy. There was no history of maternal illness during the antenatal period and no neonatal/childhood febrile illness or exposure to ototoxic drugs. The motor developmental milestones were not delayed. There was no history of similar conditions among other members of her family.

Physical examination revealed a healthy girl with no facial or physical abnormalities.

Ocular examination revealed a visual acuity of 20/20 with the illiterate E-chart, decreased bilateral central corneal thickness (right eye $496 \mu \mathrm{m}$ and left eye $-489 \mu \mathrm{m})$, right partial heterochromia iridium, left complete hypoplastic blue irides, hypopigmented fundi and no dystopia canthorum (Figure 5). The inner inter-canthal distance, the outer intercanthal distance and inter-pupillary distance measured $30 \mathrm{~mm}, 87 \mathrm{~mm}$ and $6 \mathrm{~mm}$ respectively and the $\mathrm{W}$-index was 1.49 .

ASSRA also showed a profound sensorineural hearing loss as represented in Figure 6.

All the three children were diagnosed with WS Type 2 .

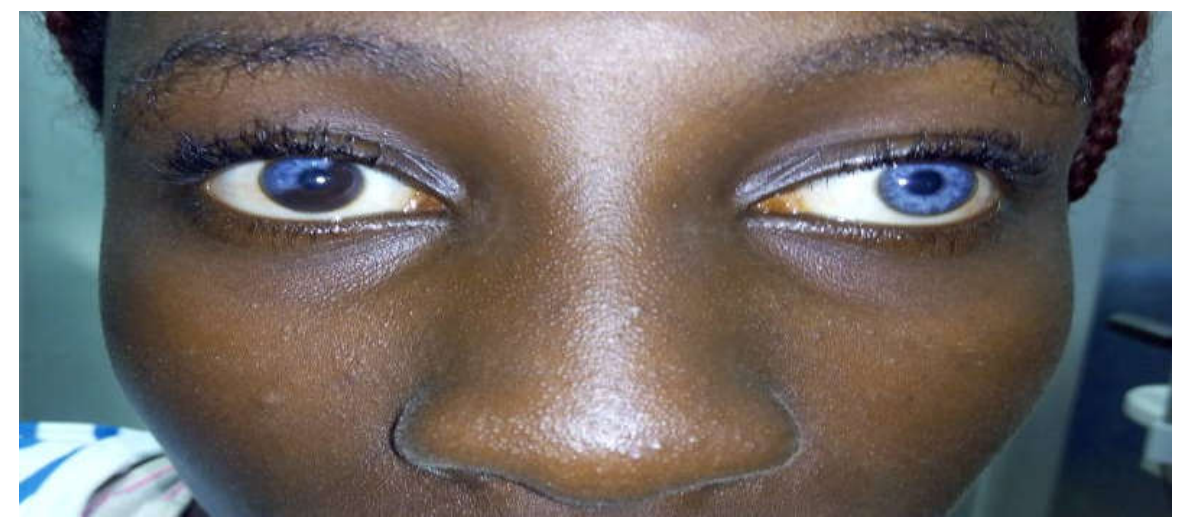

Figure 5: Right partial heterochromia iridium and left complete hypoplastic blue iridium in Case 3 


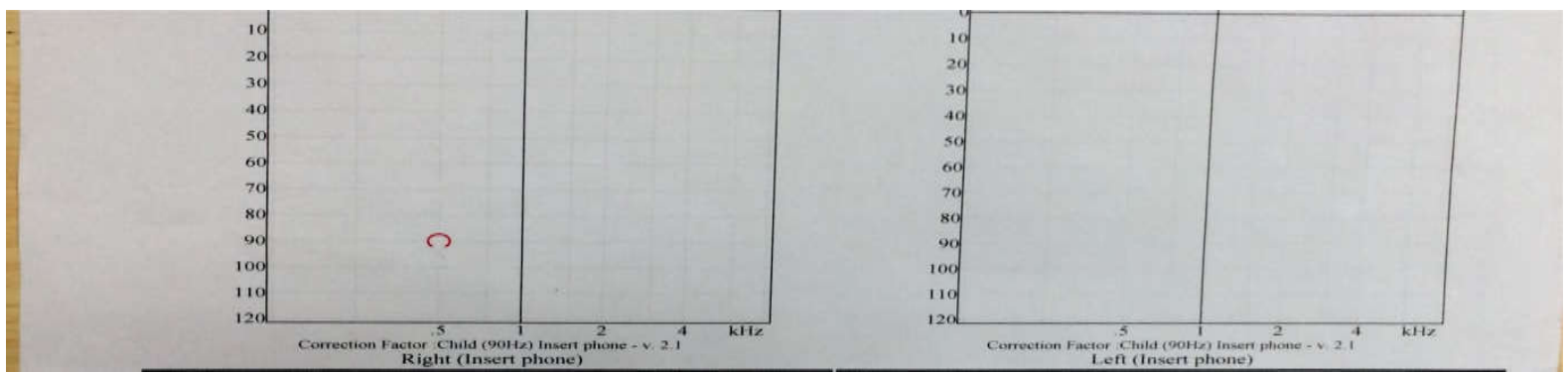

Figure 6: Audiometric pattern of profound sensorineural hearing loss in Case 3

\section{Discussion}

Waardenburg syndrome as a clinical entity is divided into subtypes (WS1-4\} based on variable penetrance and expression of its genes. WS Type 1 is an auditory-pigmentary disorder comprising sensorineural hearing loss and pigmentary disturbances of the eye, skin and the hair as well as dystopia canthorum. [11] The presence of dystopia canthorum is important in WS Type 1 and has been shown to be present in $99 \%$ of those affected. [12] Dystopia canthorum is absent in WS Type 2. All the three cases presented here are of Type 2 disease. Ocular features seen in WS include heterochromia of the iris/irides which can take the forms of complete heterochromia iridium, partial or segmental heterochromia, hypoplastic blue eyes [3] and pigmentary changes on the retina. [10] Complete bilateral hypoplastic blue eyes were noticed in two of the patients in this report while one patient had complete hypoplastic blue iridium in one eye and partial heterochromia iridium in the other eye. In a similar study in Northern Nigeria, all four patients reported by Ahmed et al [6] had complete blue irides. However, they also had white forelock which was not present in the present series. The patients described by Ahmed et al ${ }^{[6]}$ had WS Type 1. Dourmishev et al reported that hypoplastic blue irides occurred in $14.9 \%$ to $42 \%$ of cases. ${ }^{[13]}$ Goldberg described the association of bilateral irides and hypochromic /hypopigmented fundus, though, this is not included in the diagnostic criteria for WS. ${ }^{[14]}$ All the three cases in the present series had hypopigmented fundi.

Hearing loss could be due to lack of melanocytes in the stria vascularis of the cochlea. [15] Cochlear degeneration in the form of lack of hair cells in the organ of Corti and atrophy of stria vasularis with lack of melanocytes was seen in a case of Waardenburg syndrome described by Merchant et al. [16] Congenital hearing loss is a major feature in most cases of WS. This is usually sensorineural and non-progressive, with a penetrance of $69 \%$ in WS Type 1 and $87 \%$ in WS Type 2. [17] This was a prominent feature in all the three cases described in the present series. The hearing loss may be unilateral or bilateral and may vary from mild to profound. All the three cases presented here have bilateral severe to profound hearing loss. This finding also correlates well with a similar report by Ahmed et al. ${ }^{[6]}$ However, hearing loss was assessed by Ahmed et al using the tuning fork method which is subjective. [6]

Auditory Steady State Audiometry was used because it is a more objective, sophisticated and statistic based algorithm useful for detecting and defining a hearing threshold. [18] It is a binaural device that evaluates broadband frequencies simultaneously. In addition, it estimates hearing threshold from mild to profound hearing loss and offers more spectral information within a shorter frame of time. ${ }^{[18]}$ Other types of objective audiometry include auditory brainstem responses (ABR) and otoacoustic emission. ASSR produces 
audiogram of hearing threshold while $A B R$ produces a wave which needs more expertise to interpret. Otoacoustic emission, however, tests the integrity of the outer hair cells of the cochlea.

Cutaneous pigmentary defects occur in 8.3 to $50 \%$ of WS patients. [13] Piebaldism-like features may appear in patients with WS. [3,13] A white forelock may appear in the hair which can also involve the forehead but may occur elsewhere. Goldberg et al reported that premature greying of scalp hair, eyebrows, cilia or body hair occur in $7 \%$ of cases. [14] However, these cutaneous pigmentary defects were not seen in any of the children described in this series.

WS may be diagnosed at birth or early childhood based upon a thorough clinical evaluation, identification of characteristic physical findings and various specialized studies. Diagnostic evaluation may involve the use of a calliper to measure the inner intercanthal distance, the outer angles of the eyes and inter-pupillary distances. These dimensions were within normal ranges in all the three cases in this report when compared with values obtained in a study of Nigerian Ijaws. ${ }^{[19]}$ Researchers indicate that obtaining and evaluating a composite of these measurements (i.e. using a predefined biometric index known as the "W-index") may be helpful in confirming the presence or absence of dystopia canthorum, a finding which may suggest WS1. [3,5] The W-index values were normal in the three patients described in this series. Additional diagnostic studies may be conducted to detect or characterize certain abnormalities potentially associated with WS. Such studies may include slit-lamp examination, specialised hearing tests and/or advanced imaging techniques required to evaluate inner ear abnormalities, skeletal defects (as seen in WS Type 3) and Hirschsprung disease (as seen in WS Type 4).
The treatment of WS is directed towards the specific symptoms that are apparent in each individual. Such treatment may require the coordinated efforts of a team of medical professionals, such as the dermatologists, ophthalmologists, otorhinolaryngologist, audiologist, orthopaedic surgeon, gastroenterologists, speech-language pathologists, and physiotherapists.

Early recognition of sensorineural deafness plays an important role in ensuring prompt intervention and appropriate supportive management. Therefore, there is a need to create more awareness of WS. Assessment of hearing functions is done objectively to detect hearing loss. All the three cases will require a cochlear implant, a device in which electrodes implanted in the inner ear stimulate the auditory nerve to send impulses to the brain. In addition, early special instruction may be recommended to assist in the development of speech and certain methods - sign language, lip reading and the use of communication devices to aid communication. However, in our environment access to cochlear implant is difficult and the only available option is the use of hearing aid. Interestingly, all the three children in this series were being taught sign language in the Special Education Schools they attended. Most of the cases of congenital hearing loss are not detected early in Nigeria as there is no established hearing screening program for the country.

\section{Conclusion}

Three cases of Waardenburg syndrome Type 2 detected among the pupils of Special Education Centres in south-western Nigeria with severe to profound sensorineural hearing loss but no visual impairment have been described. Sensorineural hearing loss with attendant lack of speech is a major challenge in the affected children. Therefore, there is a need for early hearing screening, health education 
and rehabilitation to prevent deaf-mutism in the affected children.

Authors' Contributions: All the authors (BAO, AMA, JOO, OOY and SOF) were involved in the conception, acquisition and interpretation of the data; drafting of the manuscript and revising it for intellectual content. They were also all involved in the final approval of the version to be published and have agreed to be accountable for all aspects of the study.

Conflict of interest: None declared.

Funding: None.

Publication History: Submitted 29 January 2018; Revised 09 May 2018; Accepted 18 June 2018.

\section{References}

1. Waardenburg PJ. A new syndrome combining developmental anomalies of eyelid, eyebrows and nose root with pigmentary defects of iris and head hair and congenital deafness. Am J Hum Genet 1951; 3: 195-253.

2. Tamayo M, Galvez N, Rodriguez M, Florez S, Varon C, Medina D, et al. Screening Program for Waardenburg syndrome in Colombia: Clinical definition and phenotypic variability. Am J Med Genet 2008; 146A: 1026-31.

3. Read AP, Newton VE. Waardenburg syndrome. J Med Genet 1997; 34: 656-65.

4. Gene Reviews. Milunsky JM. Waardenburg syndrome Type 1 . Available at

http://www.ncbi.nlm.nih.gov/books/NB K1531/. Posted July 20, 2001 (Updated December 29, 2011) and accessed on November 10, 2017.

5. Mehta M, Kavadu P, Chougule S. Waardenburg syndrome. Indian $\mathrm{J}$ Otolaryngol Head Neck Surg 2004; 56(4): 300-2.

6. Ahmed AO, Samaila E, Abah ER, Oladigbolu KK, Merali H, Abubakar A. Audiometric findings in Waardenburg syndrome amongst the institutionalised deaf/blind in Kaduna -Nigeria. Niger J Med 2011; 20: 28-32.

7. Morell R, Carey M.L, Lalwani AK, Friedman TB, Asher JH Jr. Three mutations in the paired homeodomain of PAX3 that cause Waardenburg syndrome Type 1. Hum Hered 1997; 47: 38-41.

8. Lautenschhlager NT, Milunsky A, Destefano A, Farrer L, Baldwin CT. A novel mutation in the MITF gene causes Waardenburg syndrome Type 2. Genet Anal 1996; 13: 43-4.

9. Tachibana M, Takeda K, Nobukuni Y, Urabe K, Long JE, Meyers KA, Aaronson SA, Miki T. Ectopic expression of MITF, a gene for Waardenburg syndrome Type 2, converts fibroblasts to cells with melanocytes characteristics. Nat Genet 1996; 14: 50-4.

10. Bist J, Adhikari P, Sharma AK. Waadenburg syndrome. Clin Exp Optom 2011; 94(2): 240-2.

11. Karaman A, Aliagaolu C. Waardenburg syndrome type 1 . Dermatol online J 2006; 12: 21 .

12. Arias S, Mota M. Apparent non-penetrance for dystopia in Waardenburg syndrome type 1 with some hints on the diagnosis of dystopia canthorum. J Genet Hum 1978; 26: 101-31.

13. Dourmishev AL, Dourmishev LA, Schwartz RA, Janniger CK. Waardenburg syndrome. Int J Dermatol 1999; 38: 656-63.

14. Goldberg MF. Waardenburg syndrome with fundus and other anomalies. Arch Ophthalmol 1966; 76; 797-810.

15. Garg U, Surana R. Waardenburg syndrome 2. Indian J Otol 2012; 18: 220-22.

16. Merchant SN, McKenna MJ, Milunsky A, Baldwin CT, Nadol JB. Otopathology in a Case of Type 1 Waardenburg Syndrome. Ann Otol Rhinol Laryngol 2001; 110: 87582. 
17. Newton V. Hearing loss and Waardenburg syndrome: Implications for genetic counselling. J Laryngol Otol 1990; 104: 97103.

18. Lin $\mathrm{YH}, \mathrm{Ho} \mathrm{HC}, \mathrm{Wu} \mathrm{HP}$. Comparison of auditory steady-state responses and auditory brainstem responses in audiometric assessment of adults with sensorineural hearing loss. Auris Nasus Larynx. 2009; 36: 140-5.

19. Osunwoke EA, Didia BC, Olotu EJ, Yerikema AH. A study of the normal values of inner canthal, outer canthal, interpupillary distance and head circumference of 3-21 years Ijaws. Am J Sci Ind Res 2012; 3(6): 441-5. 